\title{
NOSSOS CORPOS NOS PERTENCEM: O SUJEITO DE DIREITO NO DISCURSO FEMINISTA
}

\author{
LAÍS VIRGINIA ALVES MEDEIROS ${ }^{1}$
}

Instituto de Estudos da Linguagem, Universidade Estadual de Campinas

R. Sérgio Buarque de Holanda, 571 - Cidade Universitária, Campinas - SP - Brasil

lais.v.medeiros@gmail.com

\begin{abstract}
Resumo. O presente artigo busca, com base nos estudos de Haroche (1992) e Edelman (1976), traçar uma retomada teórica da noção de sujeito de direito, procurando estabelecer relações entre o funcionamento da subjetividade e o funcionamento do jurídico. Em seguida, essa noção será articulada em suas possíveis relações com um slogan muito vigente no movimento feminista, "nossos corpos nos pertencem", e sua paráfrase "meu corpo, minhas regras". Essa análise visa observar como o discurso feminista é atravessado pelos pressupostos do sujeito de direito e como esse atravessamento é passivel de abrigar contradições, conflitos e silenciamentos.
\end{abstract}

Palavras-chave: sujeito de direito; discurso feminista; slogans feministas.

\begin{abstract}
This article, based on the studies of Haroche (1992) and Edelman (1976) attempts to present a theoretical revision of the notion of subject of law, seeking to relate the functioning of subjectivity and functioning of the juridical. Then, that notion will be articulated in its possible relations to a well-known slogan in feminist movement, "our bodies belong to us", and its paraphrase "my body, my rules". This analysis has the objective of observing how feminist discourse is crossed by law presupposes and how this crossing may contain contradictions, conflicts and silencings.
\end{abstract}

Keywords: subject of law; feminist discourse; feminist slogans.

\section{INTRODUÇÃO}

Da Declaração Universal dos Direitos Humanos, que afirma em seu primeiro artigo "Todos os seres humanos nascem livres e iguais em dignidade e direitos.", à Constituição da República Federativa do Brasil, que afirma em seu quinto parágrafo "Todos são iguais perante a lei, sem distinção de qualquer natureza, garantindo-se aos brasileiros e aos estrangeiros residentes no País a inviolabilidade do direito à vida, à liberdade, à igualdade,

\footnotetext{
${ }^{1}$ Doutoranda em Linguística (Bolsista CNPq), no Instituto de Estudos da Linguagem da Universidade Estadual de Campinas.
} 
à segurança e à propriedade", parecem existir dois pontos pacíficos: existem sujeitos caracterizados pela liberdade, e esta liberdade é reforçada e assegurada pelo campo jurídico. O que a leitura de autores como Haroche e Edelman permite é a deslinearização desse pressuposto, pela retomada de um percurso que demonstra o quanto esta, que parece hoje uma obviedade, na verdade é uma construção indissociável de atravessamentos históricos que compunham diferentes formas de sujeitos até chegar à que temos hoje.

Nesse sentido, proponho neste artigo uma breve retomada teórica das análises desenvolvidas pelos autores, para por fim associá-las à questão: qual é o funcionamento do pressuposto do sujeito de direito dentro do discurso feminista? Como ele pode ser analisado tomando como base alguns slogans de grande circulação desse movimento?

\section{O SUJEITO ENTRE A RELIGIÃO E O DIREITO}

Embora a escrita de Haroche (1992) se baseie no contexto político da França, desdobramentos semelhantes podem ser identificados em demais sociedades ocidentais. É assim que constatamos, por exemplo, um imperativo econômico delineando diferentes formas de sujeito e diferentes formas de este se relacionar com o saber. O que permanece na transição de uma forma a outra é o assujeitamento a algo exterior: seja à Igreja, seja ao Direito. A possibilidade (ou interdição) da ambiguidade na língua é o fio condutor que Haroche toma para acompanhar essas mudanças.

Sobre a influência do imperativo econômico, Haroche (1992) aponta que a ideia de lucro surge já entre os séculos XI e XIII, modificando o sistema de subsistência que vigorava até então. De um lado, havia os comerciantes e artesãos, que precisaram se organizar como classe trabalhadora em torno de reivindicações, numa estrutura um tanto semelhante à do sujeito de direito como conhecemos hoje. De outro lado, as relações campesinas se organizavam com demandas diferentes. Se os camponeses compravam sua liberdade de seus senhores, essa liberdade vinha com o custo de um endividamento, gerando assim uma nova sujeição, desta vez pela via do Direito. A liberdade, princípio básico do sujeito de direito, surge aqui já associada ao poder econômico (um desdobramento ainda identificável na forma contemporânea de sujeito de direito).

Quanto à língua, a autora parte da necessidade de não contradição característica da ordem religiosa: sem a possibilidade de ambiguidade e interpretação, assegura-se uma completa subordinação do sujeito ao texto e ao dogma. Essa subordinação, no entanto, estabelece uma relação contraditória com a necessidade de expansão econômica, motivo pelo qual o Direito passa gradualmente a ocupar o lugar de circunscrição do sujeito que a Igreja anteriormente ocupava. A introdução dos textos aristotélicos na Universidade de Paris no século XIII marca a crise da dupla verdade, expondo a discordância entre os saberes da Igreja e os saberes da Ciência, bem como fomentando o enfraquecimento da Igreja e o fortalecimento do jurídico. Se até então qualquer manifestação de autonomia do sujeito era classificada como heresia, o que repercutia na obrigação da reprodução sem questionamentos dos dogmas religiosos, sua relação com o saber sofre alterações graduais, devidas em parte à lógica e à retórica. É no século XVI, com a emergência da Reforma Luterana, que o ideal de liberdade do sujeito progride e indica uma nova forma de assujeitamento ao religioso: para se submeter, é preciso antes compreender. Nesse movimento, a determinação institucional pedagógica vem substituir a determinação 
religiosa; essa substituição não é permanente, e logo dá lugar à determinação individual, emergência significativa no período que precede a Revolução Francesa.

Haroche (1992, p. 82) aponta já nos escritos de Lutero a importância dada à liberdade, como "um verdadeiro manifesto humanista que conduzirá à ideia de não determinação do sujeito". É assim que o humanismo desponta como uma expressão de que o sistema jurídico estava se sobrepondo, gradual e definitivamente, à ordem religiosa, sobreposição que muda o modo de assujeitamento: sujeitos livres para livremente se assujeitarem. A autora conclui que, após a Revolução Francesa, instaura-se no século XVIII a centralidade do sujeito e da subjetividade, prevalência que trará consequências para a língua e para a gramática.

Nesse sentido, interessa reter que o sujeito é sempre assujeitado a algo que lhe é exterior. Assim como fora assujeitado à Igreja, atualmente é ao Estado e, com isso, assegura-se o funcionamento do jurídico: pela crença na letra, na lei, na certeza de que as coisas são como deveriam ser e de que o Direito serve para garantir isso. Enquanto Haroche identifica, ao fim de sua análise, que o Direito não é questionado, Edelman propõe analisar como o sujeito de direito foi construído e legitimado nesse âmbito de certezas.

\section{LIBERDADE, IGUALDADE, PROPRIEDADE}

Ao propor um “discurso teórico da prática jurídica”, Edelman (1976) estabelece desde o princípio que o Direito serve à propriedade privada numa espécie de santificação. Para o autor, há uma dupla função necessária no funcionamento jurídico: por um lado, a de tornar eficazes as relações de produção; por outro, a de refletir e sancionar as ideias que as pessoas têm sobre as relações sociais. E não apenas sobre as relações, mas também sobre si mesmo: o sujeito de direito é uma construção sólida do funcionamento do jurídico.

Edelman explica que embora saibamos o que é o Direito, não sabemos como ele funciona. $\mathrm{O}$ autor propõe uma explanação sobre esse funcionamento, começando por afirmar a existência de uma ideologia jurídica, cujas fronteiras o Direito se esforça em traçar. O nascimento dessa ideologia se deu pelo postulado de que o homem é um proprietário em potência: a propriedade privada é a hipótese de base do Direito. Edelman apresenta a categoria de sujeito de direito como uma noção ideológica, que define o homem naturalmente como sujeito (mesmo que não queira ser) e, portanto, em posição de assumir direitos e obrigações. Nesses termos, a liberdade é tomada como a capacidade jurídica do sujeito de direito pertencer a si mesmo e, pertencendo a si mesmo, poder adquirir.

O autor salienta como a força de trabalho é um dos bens passíveis de compra e venda: sendo proprietário de si mesmo, o sujeito pode vender sua força, usá-la como moeda de troca, dela obter um rendimento; uma vez que essa propriedade não esteja à venda, ou esteja sob custódia de outra pessoa (como no caso da escravidão), a pessoa não ocupa mais a posição de sujeito, mas, sim, de objeto. É por isso que não podemos deixar de pensar no trabalho (ainda que como hipótese ou potencialidade) como fator constitutivo da subjetividade.

Como fio condutor de sua análise, Edelman toma as mudanças que os direitos relacionados à produção e à criação sofreram com a introdução de diferentes tecnologias 
no meio artístico: a fotografia e o cinema. $\mathrm{O}$ autor salienta que foi preciso contornar o conteúdo contraditório das propriedades literária e artística, num jogo entre o material e o imaterial: reconhecer o sujeito de direito como criador dá a ele direitos sobre sua criação, um ponto que será mais ou menos pacífico a depender da criação que for avaliada. No caso da literatura, por exemplo, existe a defesa de que a essência do criador estaria no texto, e por isso seus direitos sobre aquela obra devem ser assegurados. Já no caso da fotografia, num primeiro momento, esta era lida como produto de uma máquina, e não de um sujeito, não havendo nela resultado de criação subjetiva. Um funcionamento semelhante aconteceu com a emergência do cinema. O que Edelman frisa é que foram as relações de produção e suas exigências que definiram o reconhecimento de fotógrafos e cineastas como criadores: a necessidade da indústria subordinou a estética ao comércio. É devido à reiteração desse funcionamento, com as relações de produção delineando o jurídico e o sujeito de direito, que Edelman (1976, p. 74) afirma que "o verdadeiro sujeito criador é o capital".

Os debates em torno dos direitos artísticos são exemplos tomados para pensar um processo que se estende para muito além desse âmbito e atravessa a constituição do sujeito. Partindo de Marx e de sua definição de sociedade civil como noção ideológica, Edelman (p. 141) lembra que as categorias que fundamentam essa noção ("propriedade privada, sujeito, vontade, liberdade, igualdade") são transformadas pela ideologia jurídica, que as especifica: não mais apenas sujeito, mas, sim, "sujeito de direito". Tratase de uma imposição da ideologia jurídica.

As implicações desse desdobramento para a subjetividade são notáveis. Ao mesmo tempo em que o direito sanciona as relações de produção para o sujeito, ele também revela a relação imaginária deste com aquelas, de modo a consagrar a propriedade privada como "essência histórica" do indivíduo. Na eficácia desse funcionamento, o indivíduo se constitui e age como se, de fato, fosse esta a sua essência. O direito, por sua vez, vem legitimar essa construção, manifestando "realmente/ideologicamente, pela coação do aparelho de Estado, as determinações do valor de troca (propriedade/liberdadeigualdade)" (EDELMAN, 1976, p. 142). Se a propriedade é o que define o sujeito, e essa propriedade é mobilizada a serviço de trocas baseadas em liberdade e igualdade, logo a propriedade de si próprio (e a liberdade de se colocar em relações de troca) é "a mais desenvolvida Forma do sujeito".

O que saliento dessa retomada de Edelman é como a liberdade e a propriedade se relacionam de modo complementar, constituindo o sujeito de direito de tal modo que esses princípios não sejam questionados. Os questionamentos, quando ocorrem, baseiamse na contradição constatada nesses princípios, como será possível observar na análise dos slogans selecionados nas relações que estabelecem com diferentes demandas do movimento feminista.

\section{"NOSSOS CORPOS NOS PERTENCEM": COMO O SUJEITO DE DIREITO FUNCIONA NO DISCURSO FEMINISTA?}

Em minha pesquisa de doutorado, investigo os sentidos de "empoderamento" no discurso feminista em ambiente digital. A seleção do corpus desenvolvida até o momento aponta que o termo tem sido mobilizado nos contextos mais diversos: desde emancipação 
econômica a violência doméstica, passando por saúde sexual e venda de maquiagem. $\mathrm{Na}$ breve análise que proponho aqui, meu interesse se volta a um slogan que por vezes é retomado ao tratar de empoderamento, embora seja mobilizado também independentemente: "nossos corpos nos pertencem".

Esse mote do movimento feminista que remonta à década de 1970 ainda se faz presente na quarta onda feminista e é atualizado por paráfrases como "meu corpo, minhas regras". A definição de paráfrase que tomo para esta análise é aquela apresentada por Pêcheux (2009 [1975], p. 266), denominada de "histórico-discursiva". Para o autor, o funcionamento parafrástico é necessário numa "formação discursiva historicamente dada", de modo que a paráfrase discursiva se diferencia da paráfrase puramente sintática. Em minha dissertação de mestrado (MEDEIROS, 2016), delimitei a formação discursiva feminista como aquela que tem como saber central, constitutivo de sua forma-sujeito, a luta pelos direitos das mulheres. É por esse motivo que situo os slogans aqui apresentados dentro dessa formação discursiva em comum, e identifico-os numa relação parafrástica.

Ao pensar o slogan "nossos corpos nos pertencem" à luz das escritas de Haroche e Edelman, meu objetivo é traçar uma relação entre esse slogan e a falsa transparência do sujeito de direito como sujeito livre, marcado pela propriedade de si mesmo e legitimado pelo discurso jurídico. Ao propor, na esteira desses autores, a emergência do Mercado como um novo grande sujeito, Payer (2005, p. 14; grifos da autora) sustenta que "em cada tempo histórico há máximas que funcionam como fundamentais, enquanto máximas capazes de condensar o conteúdo que exerce a 'interpelação ideológica dos indivíduos em sujeito"'. Nesse sentido, esse slogan feminista pode ser lido como uma máxima fundamental que mobiliza e tensiona duas discursividades: a do sujeito de direito, assujeitado ao Estado e ao funcionamento jurídico, e a de um sujeito inscrito dentro de uma formação discursiva específica, qual seja, a feminista.

Como minha pesquisa se desenvolve a partir do ambiente digital, pesquisei em blogs e sites a sequência "nossos corpos nos pertencem" para analisar os sentidos que esse slogan retoma nos textos em que é evocado, o que é enunciado e o que é silenciado em relação a ele e como essas relações podem ser pensadas à luz da noção de sujeito de direito.

O primeiro recorte que trago é da convocatória para um ato unificado marcando o Dia Internacional da Mulher ${ }^{2}$ em 2012, no Recife. O slogan "nossos corpos nos pertencem" é apresentado no título, de onde é possível interpretar que será este o tema central da manifestação. A convocatória integral é a seguinte (grifos meus):

\section{8 de Março de 2012: movimento de mulheres reafirmam "nossos corpos nos pertencem!" A partir das 15h, na Praça do Diário, centro do Recife, ato público unificado marcará \\ o Dia Internacional da Mulher.}

Para unir forças, neste 8 de Março - Dia Internacional da Mulher, movimentos de mulheres do Recife realizam um ato unificado, a partir das $15 \mathrm{~h}$, na Praça do Diário, Centro do Recife, Pernambuco. O ato será por liberdade e autonomia. Entre as organizações do movimento de mulheres, é consenso a necessidade de enfrentar os ataques à dignidade

2 Disponível em http://matizesfeministas.blogspot.com/2012/03/nossos-corpos-nos-pertencem.html. Acesso em 22 jun. 2018. 
feminina e marcar a manifestação com diversas expressões feministas pela liberdade e autonomia das mulheres.

Cerca de 200 mulheres irão se unir contra: o controle do corpo pelo Estado e a violação masculina por meio da violência sexual; contra a mercantilização e exploração do corpo das mulheres pela medicina estética, pela pornografia, pela propaganda, e contra a mercantilização da maternidade. Com faixas, cartazes, panfletos, dizeres e músicas, as feministas irão demonstrar combatividade e disposição para luta.

É possível observar a evidência de um sujeito de direito se desdobrando de diferentes modos nessa convocatória. Num primeiro aspecto, ela se desdobra no reforço da liberdade e da autonomia das mulheres: inicialmente apresentadas como o mote do ato, em seguida elas figuram como uma necessidade consensual (apagando a heterogeneidade que é própria do movimento feminista). Os sentidos de liberdade e autonomia, próprios do sujeito de direito, não são trabalhados em sua opacidade. Se por um lado o Estado respalda a ideologia jurídica e com isso o sujeito de direito, é o mesmo Estado que relativiza sua liberdade: pela Constituição, algumas restrições são impostas aos corpos, restrições lidas como uma forma de controle que limita a liberdade e a autonomia femininas, principalmente no que diz respeito aos direitos reprodutivos. No Brasil, exceto em três casos excepcionais (risco de vida da gestante, gestação resultante de estupro e feto anencéfalo ${ }^{3}$ ), o aborto é crime. A evocação da propriedade do corpo nas pautas feministas pode ser lida como uma falha no ritual: enquanto sujeito de direito, é possível levantar essa contestação com base no discurso jurídico; no entanto, o que é contestada é justamente a intervenção da ideologia jurídica na liberdade que devo ter sobre a minha propriedade (meu corpo).

Mas não é apenas contra o Estado que essa demanda por liberdade se volta. Na mesma sequência, é evocada "a violação masculina por meio da violência sexual". $\mathrm{O}$ assunto é passível de ser analisado por diferentes pontos de vista teóricos, mas, para me ater ao propósito desta análise, retomo a alternância sujeito-objeto que Edelman explica ao tratar da potencialidade da força de trabalho enquanto moeda de troca. Nas situações em que o sujeito não é proprietário de si mesmo, como no caso da escravidão, ele não pode mais ser lido como sujeito, mas como objeto. Embora a violência sexual não esteja necessariamente relacionada às relações de trabalho ${ }^{4}$, ela pode ser lida como uma apropriação do corpo alheio de forma desrespeitosa à sua vontade, o que fere a autonomia do sujeito de direito e o coloca numa posição de objeto. Assim, quando o controle do Estado e a violência sexual são elencados em sequência nessa convocatória, o que se destaca é uma dupla objetificação da mulher: objeto porque submetida a duas situações em que a propriedade de seu corpo lhe é negada, não podendo escolher nem o que fazer com ele nem quem terá acesso a ele.

Num segundo tópico da convocatória, o protesto se volta "contra a mercantilização e exploração do corpo das mulheres pela medicina estética, pela pornografia, pela propaganda", sequência que também funciona no sentido de silenciar a heterogeneidade

\footnotetext{
3 À época da convocatória analisada, a decisão do STF que liberou a interrupção de gravidez no caso de feto anencéfalo ainda não havia sido votada (foi votada em abril de 2012), sendo permitidos abortos apenas nos dois primeiros casos.

${ }^{4}$ A questão do trabalho sexual é uma pauta espinhosa dentro do movimento feminista, cuja exploração alongaria a análise que apresento aqui para muito além de seu objetivo.
} 
do movimento feminista ${ }^{5}$ quanto a essas questões. Enquanto a vertente mais radical se posiciona contra essas práticas, classificando-as como dominações a serviço do patriarcado e do capital, a vertente mais liberal defende a liberdade de a mulher se servir do próprio corpo como for de sua vontade individual, inclusive se valendo de medicina estética, pornografia e propaganda, se assim desejar. Nesse sentido, essa demanda da convocatória se alinharia mais ao posicionamento da vertente que tem sido designada como feminismo radical, ao mesmo tempo em que trabalha mais uma vez a tensão sujeitoobjeto: para não deixar de ser sujeito de direito, é preciso se manifestar contra as práticas que objetificam as mulheres, mesmo que essa objetificação possa ser lida, do ponto de vista de uma vertente diferente, como uma manifestação da liberdade do sujeito de direito. A medicina estética, a pornografia e a propaganda seriam cerceamentos à condição de sujeito de direito ou opções frente à liberdade que lhe é própria?

Finalmente, a última pauta de protesto da convocatória é "a mercantilização da maternidade". Essa pauta, que diz respeito ao movimento de lucro em cima do processo de gestação, parto e maternagem, evoca principalmente a violência obstétrica: é mais lucrativo forçar cesarianas ou apressar partos naturais com episiotomia que respeitar o ciclo completo de horas exigido por um trabalho de parto natural. Esta se relaciona à primeira pauta, de autonomia e liberdade sobre o corpo, mas com o acréscimo da mercantilização: aqui a restrição à mulher enquanto sujeito de direito com posse sobre si é motivada pelo lucro de outro sujeito. Nesse sentido, é possível retomar Haroche, quando esta demonstra que a liberdade do campesinato surge associada à dependência econômica (era preciso que a liberdade fosse comprada). Mesmo considerando as diferenças significativas entre as situações, é interessante observar o jogo que se estabelece entre a liberdade e seu preço: a fim de agilizar os trabalhos de parto (sob a máxima "tempo é dinheiro"), objetifica-se a parturiente, desrespeitando sua autonomia; no entanto, o movimento pela humanização do parto tem crescido e se mostrado como uma possibilidade de retomada da liberdade de escolha da mulher quanto ao melhor jeito de parir. Essa liberdade, por sua vez, vem com um preço: os serviços públicos que a oferecem ainda são restritos, e o modo mais eficaz de ter acesso a um parto humanizado é pela rede privada de saúde. Assim funciona movimento perverso da mercantilização do parto: para a parturiente manter sua pressuposta liberdade, ilusoriamente garantida pela ideologia jurídica, é preciso comprá-la (possibilidade aberta apenas às que têm condições econômicas que assim permitam). No caso de essa compra não estar disponível, a parturiente corre o risco de, mais uma vez, ver sua propriedade sobre o próprio corpo desrespeitada e usada como moeda de troca para o lucro de outrem.

A análise dessa convocatória foi um exercício de relacionar os sentidos que se abrigam sob um slogan abrangente como "nossos corpos nos pertencem" aos princípios do sujeito de direito, identificando como estes se marcam, efetiva ou ilusoriamente, dentro de algumas das demandas do movimento feminista. A próxima análise, mais breve, será centrada numa paráfrase do slogan, qual seja, "meu corpo, minhas regras". O texto que serve como base foi publicado no Portal Geledés ${ }^{6}$, como contribuição de uma autora convidada, e tem como título "Meu corpo, minhas regras" (grifos meus):

\footnotetext{
${ }^{5}$ Para um aprofundamento sobre essas diferentes vertentes e demandas, consultar: PEDRO, Joana Maria. Narrativas fundadoras do feminismo: poderes e conflitos (1970-1978). REV. BRAS. HIST. vol. 26, n. 52, São Paulo, dez. 2006. Disponível em http://dx.doi.org/10.1590/S0102-01882006000200011. Acesso em 20 jun. 2018. HIRATA, Helena et. al. Dicionário Crítico do Feminismo. São Paulo: Editora UNESP, 2009. ${ }^{6}$ Disponível em https://www.geledes.org.br/meu-corpo-minhas-regras. Acesso em 22 jun. 2018.
} 
Meu corpo, minhas regras

De quem é esse corpo que habito?

Por Lelê Teles enviado para o Portal Geledés

É seu, dirás.

Não e não, retrucarei.

Acaso poso me desfazer dele quando eu bem quiser?

Minha religião diz que não, a sua religião também, qualquer religião dirá o mesmo.

"Agarra-se à sua vida, por mais miserável que ela seja", lhe impõem.

Não crês, ouça-me:

Caso eu queria dar cabo de minha vida, atentai bem, não faltará cidadãos de boa vontade para tentar me impedir.

Minha família e meus amigos se sentirão traídos se eu conseguir retirarme sem que eles me tenham consentido.

Por isso os suicidas escrevem cartas, é preciso se justificar.

A justiça só não transforma o suicídio em crime porque o autor, que por acaso também é a vítima, não pode mais ser preso.

É meu este corpo?

Por todos os lados eu vejo grilhões, baraços, algemas.

A sociedade me aprisiona e se apropria do meu corpo.

É ela quem impõe os padrões éticos e estéticos para moldar o meu corpo.

Você tá feliz com o corpo que tem? Nunca, jamais.

Você só será feliz com o corpo que a sociedade quer que você tenha e ela nunca está satisfeita!

É a sociedade que lhe impõe dietas, corpetes e corseletes.

É ela que proíbe as mães de amamentarem em público, que mata travestis pela sua ambiguidade de gênero, que define o feio e o belo, que diz quando podemos ou não podemos tatuar o nosso corpo.

Agora, por exemplo, pode!

Se não sou senhor do meu próprio corpo não posso dizer que ele me pertence.

Sou uma mera engrenagem no corpo social e, como animal cívico, estou diluído na coletividade.

Mas, o que estou a dizer?

Poderia eu de alguma forma ser senhor dessa forma que me traveste?

Não e não. Vejamos.

Eu não poderia dizer: esse braço é meu, esse nariz é meu, é minha essa boca.

Porque na verdade eu é que sou deles.

Eu não escolho: vou nascer sem a boca, o nariz ou o braço.

Porque primeiro nascem o nariz, o braço e a boca, depois é que nasço eu.

E quando nasço recebo sinais exteriores que me informam como devo usar a boca, o nariz e os braços.

Só há dois caminhos, se sujeitar ou se rebelar.

Por isso dizem que o rebelde é o único que é dono do seu próprio nariz.

Palavras sapienciais.

O texto (que para fins de referência chamarei de "manifesto"), também inserido no discurso feminista, desloca os sentidos de propriedade sobre o corpo que são convocados em "nossos corpos nos pertencem" e "meu corpo, minhas regras". Ao apontar as diferentes intervenções que um corpo sofre, o manifesto desestabiliza um sentido 
específico de liberdade e propriedade do sujeito de direito, reclamando uma liberdade e uma propriedade que sejam reais e reiterando a existência de uma liberdade utópica.

Enquanto na convocatória não havia menção direta à religião ou à Igreja, no manifesto sua influência é lembrada pela função de protecionismo à vida. É interessante observar que, embora o confronto com a religião seja mote de outro slogan feminista voltado ao corpo, qual seja, "tire seus rosários de meus ovários", os sentidos de disputa em torno do aborto e dos direitos reprodutivos não são retomados neste manifesto. A vida que a Igreja protege é a que já está fora do útero, a vida do sujeito de direito que não teria o direito de acabar com a própria vida. A menção à Igreja e seu papel moralizador pode ser pensada em relação à transição gradual que Haroche (1992) aponta do sujeito religioso para o sujeito jurídico: embora contemporaneamente o que prevaleça seja o sujeito jurídico, os traços do sujeito religioso não se apagaram por completo. Nesse manifesto, chama atenção o completo silenciamento a respeito da questão do aborto, pauta fundamental no discurso feminista: o corpo em sua possibilidade de reprodução só é evocado para falar de amamentação, momento no qual a maternidade já deixou de ser uma potencialidade e se tornou uma realidade. Se não é possível justificar o motivo desse silenciamento, é no mínimo curioso que ele aconteça num texto que reconhece a influência permanente da Igreja sobre os corpos: talvez não caiba nem mesmo citar mais uma das práticas (além do já citado suicídio) que ela proíbe.

Ao mesmo tempo em que o discurso religioso moraliza, o discurso jurídico normatiza aquilo que legalmente é permitido ou proibido. Ao relacionar o suicídio à impossibilidade de punição, o manifesto destaca uma relação curiosa do sujeito de direito com a sua condição de desde sempre já sujeito, com direitos e deveres, conforme apontada por Edelman (1976). Exercendo sua suposta liberdade sobre a própria vida, o sujeito usa de seu direito fundamental para acabar com aquilo que o estabelece a princípio como um sujeito de direito, acabando assim também com as possíveis sanções em decorrência de seus atos.

Finalmente, ao constatar que a sociedade aprisiona e se apropria do corpo, o manifesto parece se deparar com uma incompletude da noção de sujeito de direito. A liberdade, mesmo que garantida econômica e juridicamente, nunca é plena. Para além dos discursos religioso e jurídico, uma série de discursos outros condicionam o sujeito a exercer sua liberdade de modo muito limitado. As consequências a uma possível desobediência ou desvio da norma estão postas no último grifo: travestis são assassinadas porque sua ambiguidade (ou liberdade?) de gênero não é tolerável. É nesse sentido que a relação sujeito de direito-propriedade pode ser posta em tensão: ao mesmo tempo em que ele é proprietário em potencial, existe a perigosa potencialidade de ser relegado a propriedade (do Estado, da Igreja, dos discursos conservadores ou das amarras de gênero).

Uma primeira conclusão possível a partir da análise desses slogans feministas em seu funcionamento é que a potencialidade de proprietário-propriedade, ainda que não circule nesses termos, encontra-se em permanente tensão no discurso feminista. A reivindicação pelos próprios corpos, perdurando desde a década de 1970, sinaliza que o sujeito de direito em sua vontade, liberdade e igualdade esbarra em contradições que os movimentos sociais se esforçam em escancarar e combater. Talvez alguns sujeitos de direito sejam mais sujeitos do que outros, e, na análise de algumas das reivindicações do movimento feminista, o gênero parece ser o fator decisivo para hierarquizar essa diferença. 


\section{CONSIDERAÇÕES FINAIS}

A exploração da noção de sujeito de direito em seus desenvolvimentos e desdobramentos, relacionada a alguns dos motes do movimento feminista, permitiu uma reflexão sobre as falhas e a não transparência de seu funcionamento. Ainda que essa noção não seja explicitamente referenciada nos textos aqui analisados, são os seus princípios, bem como o discurso jurídico, que estão subjacentes a algumas das demandas, ao mesmo tempo em que lhes impõem limites. Reivindicar direitos sobre o próprio corpo é falar da posição de sujeito de direito, proprietário de si mesmo e resistente à possibilidade de posição de objeto ou de posse de outrem.

A ausência de referência direta ao sujeito de direito em sua vontade, liberdade e igualdade não deixa de ser uma pista de como seu funcionamento é eficaz: ainda que não nos apercebamos dele, ele nos constitui de tal modo que assumimos seus pressupostos como ponto de partida, princípio básico de qualquer reivindicação, que não precisa ser retomado ou justificado. É desse modo que a ideologia jurídica cumpre seus interesses e, quer queiramos ou não, resistamos ou não, funciona.

\section{REFERÊNCIAS}

EDELMAN, B. O direito captado pela fotografia: elementos para uma teoria marxista do direito. Coimbra: Centelha, 1976.

HAROCHE, C. Fazer dizer, querer dizer. São Paulo: Editora Hucitec, 1992.

MEDEIROS, L.V.A. Essa língua não me representa: discursos sobre língua e gênero. Dissertação. Mestrado em Letras. Programa de Pós-Graduação em Letras, UFRGS, Porto Alegre, 2016.

NOSSOS corpos nos pertencem. Matizes feministas. mar. 2012. Disponível em http://matizesfeministas.blogspot.com/2012/03/nossos-corpos-nos-pertencem.html. Acesso em 22 jun. 2018.

PAYER, M.O. Linguagem e sociedade contemporânea - sujeito, mídia, mercado. RUA, Nudecri, Labeurb, Unicamp, 11, 9-25, mar. 2005.

PÊCHEUX, M. (1975) Semântica e discurso: uma crítica à afirmação do óbvio. Trad. Bras. Campinas: Pontes, 2009.

TELES, L. Meu corpo, minhas regras. Portal Geledes. fev. 2018. Disponível em https://www.geledes.org.br/meu-corpo-minhas-regras/. Acesso em 22 jun. 2018.

Artigo recebido em: dez. de 2018.

Aprovado e revisado em: maio de 2019.

Publicado em: dezembro de 2019.

Para citar este texto:

MEDEIROS, Laís Virginia Alves. Nossos corpos nos pertencem: o sujeito de direito no discurso feminista. Entremeios [Revista de Estudos do Discurso, ISSN 2179-3514, on-line, www.entremeios.inf.br], Seção Estudos, Programa de Pós-Graduação em Ciências da Linguagem (PPGCL), Universidade do Vale do Sapucaí (UNIVÁS), Pouso Alegre (MG), vol. 18, p. 163-172, jan. - jun. 2019.

DOI: http://dx.doi.org/10.20337/ISSN2179-3514revistaENTREMEIOSvol18pagina163a172 